\title{
Research of 3-Tier Mobility Stations System with bike and car sharing- Case study of small-scale city in Germany
}

\author{
Wei Wang ${ }^{1}$, Shun $\mathrm{Su}^{2 *}$, Mengying Fu ${ }^{3}$, Yonsorena Nong ${ }^{4}$, Thomas Scriba ${ }^{5}$, Dimas Numan Fadhil ${ }^{6}$ \\ ${ }^{1}$ Research Institute of Highway Ministry of Transport. \\ ${ }^{2}$ Department of Traffic Engineering and Transport Logistics, University of Kassel, Kassel, 34125 Germany \\ ${ }^{3}$ Bauhaus Luftfahrt e. V., Munich, 82024 Germany \\ ${ }^{4}$ University of Polytechnique Montréal, Research Associate, P.O. Box 6079, Montréal, Canada \\ ${ }^{5}$ Dorsch International Consultants GmbH, Munich, 80687 Germany \\ ${ }^{6}$ Jakarta Provincial Government, Jakarta, Indonesien
}

\begin{abstract}
This paper proposed an innovative strategy for planning multimodal, integrated, intelligent, and sustainable mobility by applying 3-tiers mobility stations system combine with car sharing and bike sharing, which aims to promoting the accessibility with available transportation systems and enhance the intramodality and utilization of non-motorized transportation modes. Through the case study of the Fürstenfeldbruck city region in Germany, the 3-tiers mobility stations system concept and its planning criteria and indicators were proposed. And mobility service offerings and location selection of stations were analyzed by considering demand and coverage. Subsequently, evaluation methods based on the pre-defined indicators were implemented to the case study. The planning process is target-oriented and based on relevant structural data analysis.
\end{abstract}

\section{Introduction}

As a new and innovative strategy for planning multimodal, integrated, intelligent, and sustainable mobility, mobility stations could play an important role in cities by promoting the use of non-motorized modes (walking and cycling), public transport, shared modes (car-sharing and bike-sharing), and e-mobility[1].

Linking different transport services together is one of the main roles of mobility stations which promotes multiand inter-modality, they act as platforms to promote ecofriendly and technically innovative transport concepts which attract people to new mobility services such as carsharing and bike-sharing. By involving smartphone-based apps, mobility station services can provide real-time information and booking services in order to reduce users' barriers of using different transport modes. Additionally, mobility stations act as meeting points and public spaces. By integrating supplemental amenities such as information kiosks, bakeries, and post offices, mobility stations can assume more functions for the surrounding area[2]. Therefore, mobility stations system can be considered as an option for the improvement of intermodality and foster innovative mobility services and technologies.

There are some currently known projects in Germany. In 2003, the first model of a mobility station in Germany debuted, "Mobil.punkt", in Bremen. After that, a series of mobility stations have been built all around Germany, such as the "switch"" in Hamburg (2013), the "Münchner
Freiheit" mobility station in Munich (2014), and the "EinfachMobil" in Offenburg (2015). As a strategy to orientate people away from using their private cars, many cities have attempted to develop mobility station projects.

In this paper, the Fürstenfeldbruck city in Germany is used as the target study area, and the research tries to reduce private car travel demand and promoting the efficient travel including accessibility and intermodality in the city region by providing more efficient options for mobility through alternative modes with a new mobilitystation system.

\section{Current Situation Analysis}

Landkreis Fürstenfeldbruck is a center of attention because of its rapid growth and transformations in urban transport in recent years. While the city enjoys exciting development, transportation challenges are also evolving into great obstacles as well. Data generated by the Mobilität in Deutschland [3] study found that the District of Fürstenfeldbruck or Landkreis Fürstenfeldbruck has higher rates of car dependency than average, with longer commuting distances and a spread-out urban structure[4]. According to the report of MID[4], the modal split of Fürstenfeldbruck region indicates that private car is the most frequently used means of transport with $59 \%$ of trips. While walking and cycling have mode shares of $16 \%$ and $14 \%$ respectively, public transport has only $11 \%$ in comparison to other available means of transport. 


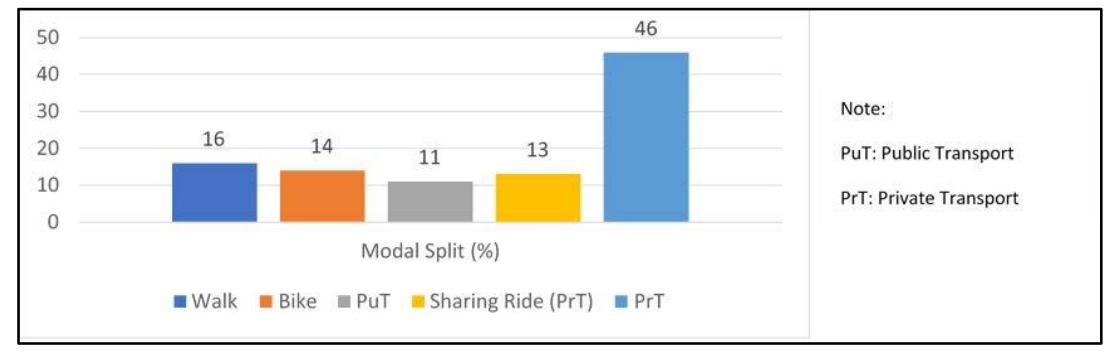

Figure 1: Modal Split in Landkreis Fürstenfeldbruck in 2008 (MVV, 2010)

Meanwhile, the car ownership of Fürstenfeldbruck indicates that only $13 \%$ households do not possess a car whereas $87 \%$ households own cars, with $51 \%$ households having access to one car. In other words, every household in Landkreis Fürstenfeldbruck has an average of 1.4 cars[4]. Notably, the high car ownership also proves that commuting with private car is the most popular choice within the city, and only those who possess no driver license cannot access a car. This can partially be explained by the sparser public transport coverage outside the city, the reduced flexibility buses offer, and the fact that cycling and walking are not competitive with the comfort provided by a private car, especially over longer distances or in bad weather. In contrast to the other transport modes, public transport occupies only $11 \%$ in mode share because of the poor public transit accessibility as well as the punctuality and reliability of the services.

The MID report also mentioned about the light rail (SBahn) connection to Munich which provides the most important railway usage in the Landkreis. Around three quarters of all S-Bahn riders from the county are riding to or from Munich[4]. The report also lists other general findings about commuters' preferences. For example, 39\% of total inhabitants in Landkreis Fürstenfeldbruck do not use or rarely use the public transport system of the city. It is likely that individuals use private car over the public transport within Fürstenfeldbruck to some extent due to the poor service and accessibility of the system.

As further proof of this, Figure 2 provides additional information regarding residents' accessibility to their workplaces by public transport. It shows that $40 \%$ of commuters rate the level of accessibility to their workplaces by public transport as bad, very bad, or as not possible. According to the interviews conducted by MVV, commuters would like to see some significant improvements of public transport in Landkreis Fürstenfeldbruck[4]. Should there be an improvement, commuters may swap their private car trips for public transport trips in the city, especially where distances are short.

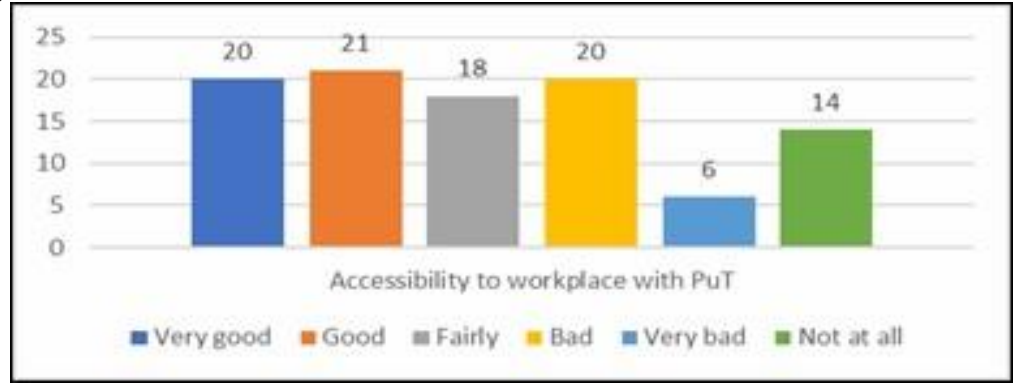

Figure 2 Accessibility to workplace with public transport (PuT)

\section{Mobility Station Solution}

Mobility stations are such a new concept in the world transport planning, existing examples from other cities in Germany were utilized as a basis for station concepts and design. However, no extensive city-wide network of mobility stations such as this exists, so the system planning was based on theoretical literature.

\subsection{The 3-Tier System concept}

During the literature review, a comprehensive document detailing the design and planning of mobility stations was found. The report published by the state of NordrheinWestfalen [5], suggested that city-wide mobility station networks should organize the stations into categories, or tiers of stations defined by their size and the amount of transport modes and services they offered. Following this idea, a 3-tier framework of mobility stations was proposed as defined below. Each station was defined by the type of area it was located, and the amount of size of the mobility station services it offered.

3.1.1. Center Stations. Center stations offer an open and green public space with a full set of mobility station services as well as connections to rail and bus transportation. Additional amenities should be present to increase the convenience and attractiveness of the stations (info points, post bins, package pickup/drop-off stations, supermarkets, ticketing machines, etc.). There were only two center stations in the system, placed at the city's SBahn stations due to the extremely high demand at these locations.

3.1.2. Sub-Center Stations. Sub-centers offered access to all mobility station services, but with fewer vehicles 
available than at center stations. Some amenities will be offered to make sub-centers more open public spaces, like package pick-up and drop-off stations in residential areas, and benches for sitting.

Sub-center stations were located at areas of major residential or commercial development, points of interest, or other popular destinations throughout the city. The selection of which areas to place sub-centers in was partially chosen to create an equal geographic dispersion of these locations throughout the city, to spread out access to all sections of the city.

3.1.3. Ancillary Stations. The lowest tier of stations is the ancillary station. These were located between the subcenter stations to proliferate access to mobility station services more equally to the throughout the city, and to supplement high-density areas which may not be entirely served by a single sub- center station. Ancillary stations were also placed in areas of relatively dense residential or commercial development, points of interest, common destinations. Many ancillary stations offered access to both car and bike sharing, however there is a subset of ancillary stations which were bike-only. These bike-only ancillary stations were spread out through the city to decrease the average walking distance to a bike station to optimize the system and attract more users. Ancillary stations in general have a limited number of vehicles per station.

\subsection{Planning Criteria and Indicators}

To elaborate upon the goal, criteria were developed to focus on its most important aspects. Efficient travel was highlighted and therefore considered as three most essential aspects. Within the scope of this paper comfortable travel is assessed based on the comfortability of using the stations, and efficient travel consists of both emissions reductions' considerations and the accessibility to new modes available at the mobility stations. The table below illustrates the breakdown of the criteria and indicators, as well as the respective units and thresholds.

Table 1: Planning Criteria and Indicators

\begin{tabular}{ccccc}
\hline Criteria & Impact Area & Indicator \& Description & Data/Units & Thresholds/Targets \\
\hline $\begin{array}{c}\text { Efficient } \\
\text { Travel }\end{array}$ & $\begin{array}{c}\text { Emissions } \\
\text { Access and }\end{array}$ & $\begin{array}{c}\text { CO2 emissions/ } \\
\text { Population with access to the } \\
\text { sccessibility }\end{array}$ & $\begin{array}{c}\text { tons } \\
\text { Availability of other services }\end{array}$ & $\begin{array}{l}\text { at least 20\% reduction of } \\
\text { private cars using } \\
\text { min. 75\% of total pop. of } \\
\text { the city within 250m of a } \\
\text { station of any type }\end{array}$ \\
\hline
\end{tabular}

\subsubsection{Indicators and Thresholds}

- $\mathrm{CO} 2$ emissions/CO2 equivalent emissions reduction. Following the goal of shifting private car demand to alternative modes, measuring the estimated change in $\mathrm{CO} 2$ emissions or $\mathrm{CO} 2$ equivalent emissions provides direct way of viewing the impact of the project. According to the emissions reduction target according to the sustainable action plan [6], the city aimed to shift $15 \%$ of car travel over to bicycles and to increase the presence of electric vehicles by $3 \%$. These goals were set in order to reach a reduction of 4,110 tons of $\mathrm{CO} 2$ emissions from the whole transport sector within 15 years (from 2005 to 2020) [6]. The threshold was defined as "at least $20 \%$ reduction of private car $\mathrm{CO} 2$ emissions compared to the situation in 2005", to attain the city's target.

- $\quad$ Population with access to the system

The population with access to the mobility station system is another indicator for assessing the impact on efficient travel. The target threshold was set at a minimum of $75 \%$ of total population of Fürstenfeldbruck City having access to a mobility station within an acceptable walking distance. The percentage of the potential population and the acceptable distance for public transport access were decided based on literature research and corresponding analysis.

Developing mobility stations system as a solution to these problems discovered during the current situation analysis. Because mobility stations are such a new concept in the world transport planning, existing examples from other cities were utilized as a basis for station concepts and design. However, no extensive city-wide network of mobility stations such as this exists, so the system planning was based on theoretical literature.

Given that most of the previous examples of mobility stations were built in cities larger than Fürstenfeldbruck, the size of the stations, the design of the system, and the role they would play in the city's transport needed to be critically considered. This role was constrained by the following conditions:

- Because of the high car dependency in the city, the system needed to provide a viable way for private car users to change their current behavior to using mobility station services.

- In order to not take riders from public transport modes, the system was planned to be supplementary to the bus system in areas where it was lacking, and complementary in areas where existing bus service is good.

- Due to the high demand in the peak hours, the mobility station system was designed to accommodate for a large flow of commuters from residential areas to the city's S-Bahn stations and large workplaces during these hours.

- The low population density of the city compared to others with mobility stations meant that the city needed a higher number of stations, each with fewer vehicles, to fulfill the same goals as a system in a more densely populated city. 


\subsection{Station Locations selection}

An iterative process was used to determine the locations of each station. The process followed the tier system, top down, placing the center stations first as their general locations were fixed at the light rail (S-Bahn) stations. Sub-center stations were successively located throughout the city, starting at the southwest end near the Buchenau light rail station, following the general curve of the city, and ending at the Fürstenfeldbruck light rail station in the northeast. The density of surrounding development, the demand created by activities at the location, the availability of a suitable area for a mobility station, and the level of access to existing public transport services were all considered when placing each sub-center station.

Once the initial placement of the sub-centers was completed, another pass through was done in order to even out the geographic distribution of the sub-centers, so that it was relatively equal across the city.
Finally, the ancillary stations were placed, beginning with the stations which offered both car and bike sharing. The specific locations for these stations were chosen by many of the same factors which controlled the locations for sub-centers, namely: the density of surrounding development, the availability of a suitable area for a mobility station, and the level of access to existing public transport services. However, the distance from another nearby station was very important in the placement of ancillary stations, as the goal was to equally distribute access to mobility station services.

Below is an overview of the locations of three tiers of mobility stations. Red hexagons represent center stations, pink diamonds the sub-center stations, and circles represent the ancillary stations. Purple circles show the ancillary stations with both car and bike sharing, and blue circles represent the bike-only ancillary stations. GIS information of the locations of each individual station can be provided upon request.

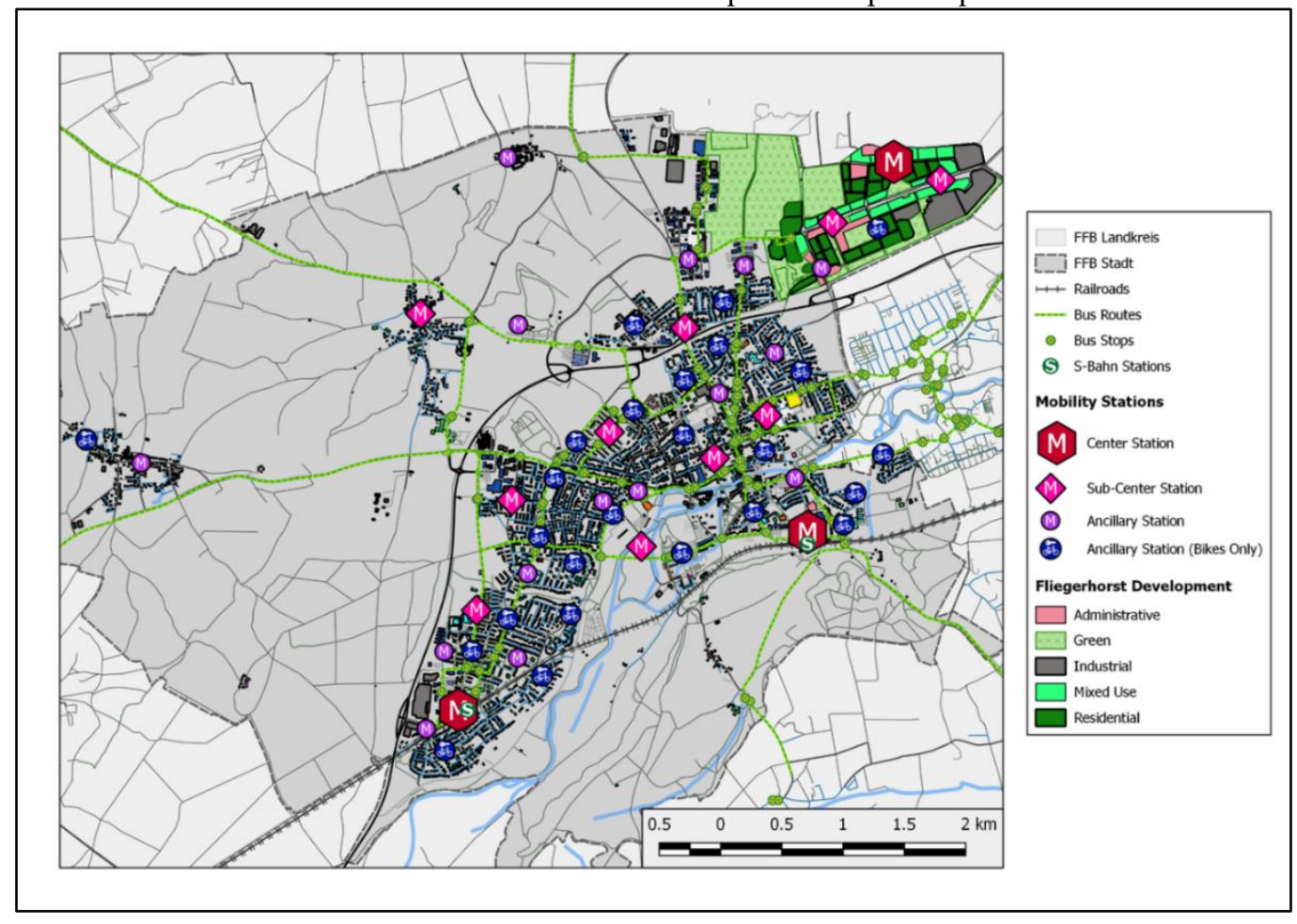

Figure 3: An overview of the planned locations of the mobility stations

\subsection{Service Offerings}

3.4.1. Capacity Calculations. After defining the 3-tier system and detailing where all the stations would be located and the phases of implementation, the amount and distribution of each type of vehicle was needed. These numbers, which describe the services offered, are based on the system's operational area and population living within that area.

For the car sharing system, first the operational area where the car-sharing system will operate within is determined. As this system was meant for intra-city travel, the operational area was confined to the residential, commercial, and industrial developments of the city. Small towns outside the city proper but still within its limits were included, but the rural farmland in between was not. The size of a fleet for a car-sharing system can be calculated by dividing the operational area by the area of a circle with a $250 \mathrm{~m}$ radius. This radius is considered as a willingness to walk distance for the prospective customers [7]. While this calculation was originally designed for a free-floating car sharing system, it results in a number of cars needed to provide the necessary capacity for a given area [8].

$$
\text { Number of Cars in Fleet }=\frac{\text { Operating Area }}{\text { Area of Walking Circles }}
$$

The total operational area for the car-sharing system, determined by GIS software was $9.43 \mathrm{~km} 2$. Therefore, by dividing the $9.43 \mathrm{~km} 2$ of operational area by the area of a 
circle with a $250 \mathrm{~m}$ radius, the resulting number of circles is 48 . Therefore, the number of cars in the car sharing system in Fürstenfeldbruck was set at 48. This number created a density of cars per square kilometer which compared similarly to the density of cars provided by other car sharing networks like car2go and DriveNow in the city of Munich.

The bike sharing system was designed based upon Bike Sharing Planning Guide (2013) from the Institute for

$$
\text { Number of Bikes in System }=\frac{\text { Number of Inhabitants }}{1000} \times \text { Bike Standard }(10 \text { bikes })
$$

The bike sharing system will use bike standard of 10 bikes per 1,000 residents. This was considered as an adequate number for bike sharing system in a suburban area with strong bike culture and a high bike ownership rate. From the calculation, the resulting number of bikes to be spread across the system was found to be 340 .

Again, following the suggestions of the ITDP guide, a bike sharing system needs to meet the minimum system coverage area to be viable, $10 \mathrm{~km} 2$. Including the areas in between development and the especially considering the changes, the coverage area of the bike sharing system would exceed $10 \mathrm{~km} 2$. Additionally, there should be at least two docks for each bike at a station, thus a total of at least 680 docks need to be provided for the system.

3.4.2. Car Sharing. The system of car sharing in Fürstenfeldbruck is a station-based system, normally requiring all the users to return the car to the station of origin at the end of their trip to avoid an extra fee. In morning peak hours, there will be an exception for ending trips at the Fürstenfeldbruck and Buchenau S-Bahn stations due to the high demand from commuters. The customer may leave their car in the dedicated parking spaces for the system, or in the regular parking lot at the S-Bahn station.

As mentioned before, in the 3-tier system, car sharing services offered are not completely equal between the station types. To define the differences between the services offered at each tier of the stations, the total fleet was divvyed up into shares for each tier of stations. The total number of vehicles of each tier's share of the total fleet was then distributed equally to each station in that tier, to create a standardized set of services for each tier.

Due to the high demand, $25 \%$ of the entire fleet will be allocated to the two center stations. Therefore, at each center station, there will be 6 vehicles assigned, 9 charging points and 3 dedicated parking spots for the car sharing system's vehicles. $40 \%$ of the fleet will be allocated to all the sub-center stations. As such, each sub-center will host 2 vehicles assigned, 3 charging points, and 2 dedicated parking spots. Finally, 35\% of the fleet will be allocated to the ancillary stations. So, in each ancillary station, 1 vehicle will be based there, along with 2 charging points and 1 dedicated parking spot. As the system develops and grows, vehicles may be shifted from one station to another, or more vehicles can be added to the system to adapt to changing demand.

As emissions reduction is one of the main objectives of the project, and the city is relatively small, a system
Transport and Development Policies (ITDP) [9]. According to the guide, the two important factors in designing a bike sharing system are population served and the minimum system coverage area. However, the number of residents served is the sole factor determining the number of bikes the system should provide. The guide concluded that bike sharing systems should provide 10-30 bikes for every 1,000 residents. The minimum bikes provided will be explained in the following equation:

entirely comprised of battery electric vehicles running on direct current (DC) was selected [10]. Such a fleet would fulfill the prerequisite of the German electrical grid and it would be capable of charging a car to a significant level of charge within 30 minutes [7].

In addition to the regular stations, there are also three stations included which do not have any vehicles assigned to them. They will be only receiving car due to the uneven demand created only during certain conditions.

\subsubsection{Bike Sharing. In Fürstenfeldbruck, Bike Sharing} is a station-based system, in which all the bikes need to be returned to a station at the end of the trip. The system will be equipped with a tracking system through radiofrequency identification devices (RFID). Unlike the car sharing system, there is no special exception for peak hours due to the excess of docks in the S-Bahn stations. In the 3-tier system, the bike sharing services are distinguished by the number of bikes assigned and docks available at each station of each tier. In both center stations, Fürstenfeldbruck and Buchenau S-Bahn stations, where $10 \%$ of total bikes are allocated, 17 bikes are provided, but 51 docks are there to handle morning rush hour and the general high demand for trips to the stations.

In each of the sub-center stations, 10 bikes are stationed along with 20 docks. In total, $30 \%$ of all bikes in the system are allocated to sub-center stations. At ancillary stations with both bike and car sharing, 30\% of total bikes are stationed. Therefore, in each of the ancillary stations, there will be 9 bikes provided with 17 docks.

Different from the car sharing system, the bike sharing system has an additional station type to reach more users, the bike-only ancillary station. This station category is not equipped with car sharing facilities. The remaining $30 \%$ of all bikes are divided into these 23 additional stations so that each has 4 bikes and 9 docks.

By providing many of these smaller bike-only stations throughout the city, using the system becomes much more attractive as the average walking distance to a station is lowered. According to the ITDP guide, the most successful bike sharing systems in the world have an average spacing of $300 \mathrm{~m}$ between stations [9].

\subsubsection{Distribution of Vehicles Among the Stations. A} summary of how many bikes and electric cars distributed to each station type is in the tables below. The total number of distributed bikes and cars are different than 
initial calculation due to some adjustment based on the station standard.

Table 2: Vehicle distributions by station tier

\begin{tabular}{cccccc}
\hline Station Tier & $\begin{array}{c}\text { \# of } \\
\text { Bikes }\end{array}$ & $\begin{array}{c}\text { \# of } \\
\text { Docks }\end{array}$ & $\begin{array}{c}\text { \# of } \\
\text { Stationed } \\
\text { EVs }\end{array}$ & $\begin{array}{c}\text { \# of } \\
\text { Charging } \\
\text { Points }\end{array}$ & $\begin{array}{c}\text { \# of Dedicated } \\
\text { Parking Spaces }\end{array}$ \\
\hline Center Station & 17 & 51 & 6 & 9 & 3 \\
Sub-Center Station & 10 & 20 & 2 & 3 & 2 \\
Ancillary Station & 9 & 17 & 1 & 2 & 1 \\
Bike-only Station & 4 & 9 & - & - & - \\
\hline
\end{tabular}

\section{Evaluation of the Mobility Stations System}

The evaluation process has been focused on efficient travel criteria, which includes indicators of Accessibility and $\mathrm{CO} 2$ emission.

\subsection{Population with Access}

The population with access to the mobility station system is a key indicator, not only for describing the level of access the population as a whole to the system's services, but also used as an intermediate step in finding the emissions reductions indicator described in a later section. This meant that the estimation of the population with access had to be calculated in a specific and reliable way, as other indicators depended on it.

The method of measuring the population by a certain radius from each mobility station was used in this paper. Many reports define this distance as a walking distance to the station, and set it around $400-500 \mathrm{~m}$. However, this walking distance does not directly translate to a circular radius around each mobility station. It was found that due to the street and pedestrian path network and topographical barriers, an area defined by a circle with a radius of $400 \mathrm{~m}$ would include residences which had actual walking distances of $700 \mathrm{~m}$ or more to the mobility station at the center.

Additionally, as mobility stations and shared transport modes would be a new transport concept for the city of Fürstenfeldbruck, it was determined that the attractive radius of a mobility station would have to be further reduced to induce a change in mobility behavior. Along with the need to count only residences which are within a specified attractive walking distance, it was determined to set the radius of the circle which defined the areas with access around each mobility station at $250 \mathrm{~m}$. This produced a conservative estimate of the population with access to the system by decreasing the size of the areas surrounding each station.

The mobility stations and the $250 \mathrm{~m}$ radius buffer zone around each station is depicted in the map below for reference.

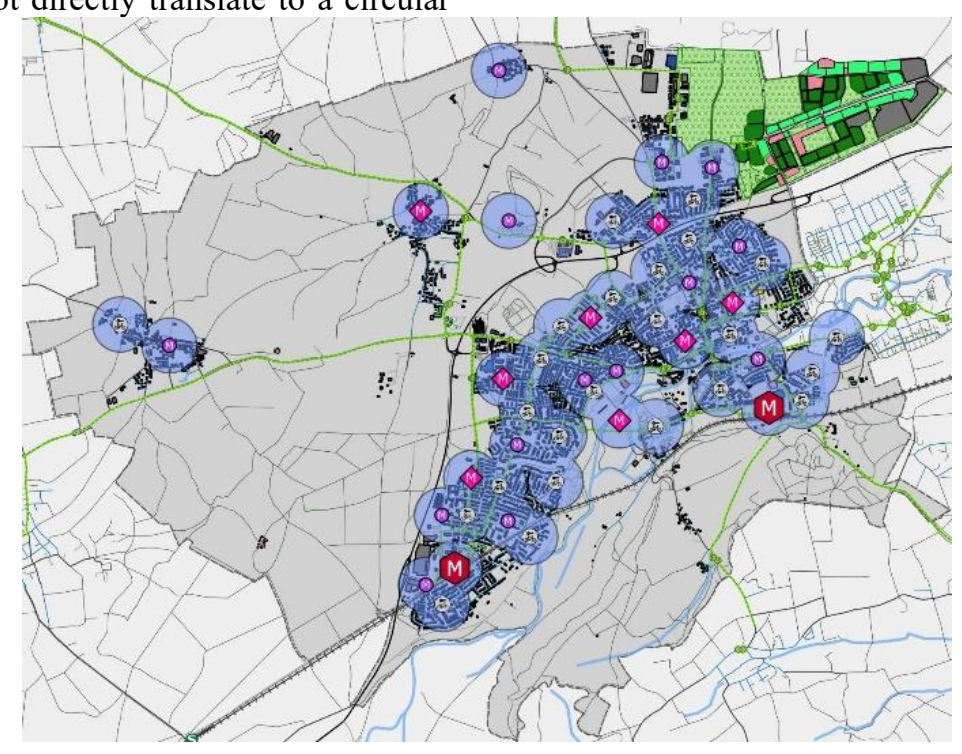

Figure 4: Mobility stations of Fürstenfeldbruck with the $250 \mathrm{~m}$ radius buffer zones for population calculate

In order to accurately calculate the population with access, population data with a high resolution is needed, or large estimation errors can distort the results. The German census completed in 2011 provided aggregate 
population data on a $100 \mathrm{~m}$ by $100 \mathrm{~m}$ grid of data points for the entire country. Each data point contained information on the number of people attributed to it. The data point grid was trimmed down to the city of Fürstenfeldbruck to create a manageable dataset in GIS. By interpolating between the points of the data grid, the number of people within each $250 \mathrm{~m}$ radius circle of attractive buffer zone around each mobility station could be estimated.

\subsection{Efficient Travel - CO2 Emission Reduction}

4.2.1. General Principle. The majority of $\mathrm{CO} 2$ emissions from the transport sector in Fürstenfeldbruck city are produced by private cars due to a high rate of

utilization [6]. Contrarily, zero emission is the key advantage of Bike and E-car sharing system. By introducing those two alternative modes, it will provide the potential opportunity to shift the transport mode with high $\mathrm{CO} 2$ emission to the mode with zero emission. From another point of view, any trip traveled by sharing system of bike and E-car could seem as a trip of $\mathrm{CO} 2$ emission reduction. Based on this principle, the prediction of $\mathrm{CO} 2$ Emission Reduction contributed by sharing systems could be calculated.

\subsubsection{E-Car Sharing CO2 Emission Reduction Calculation}

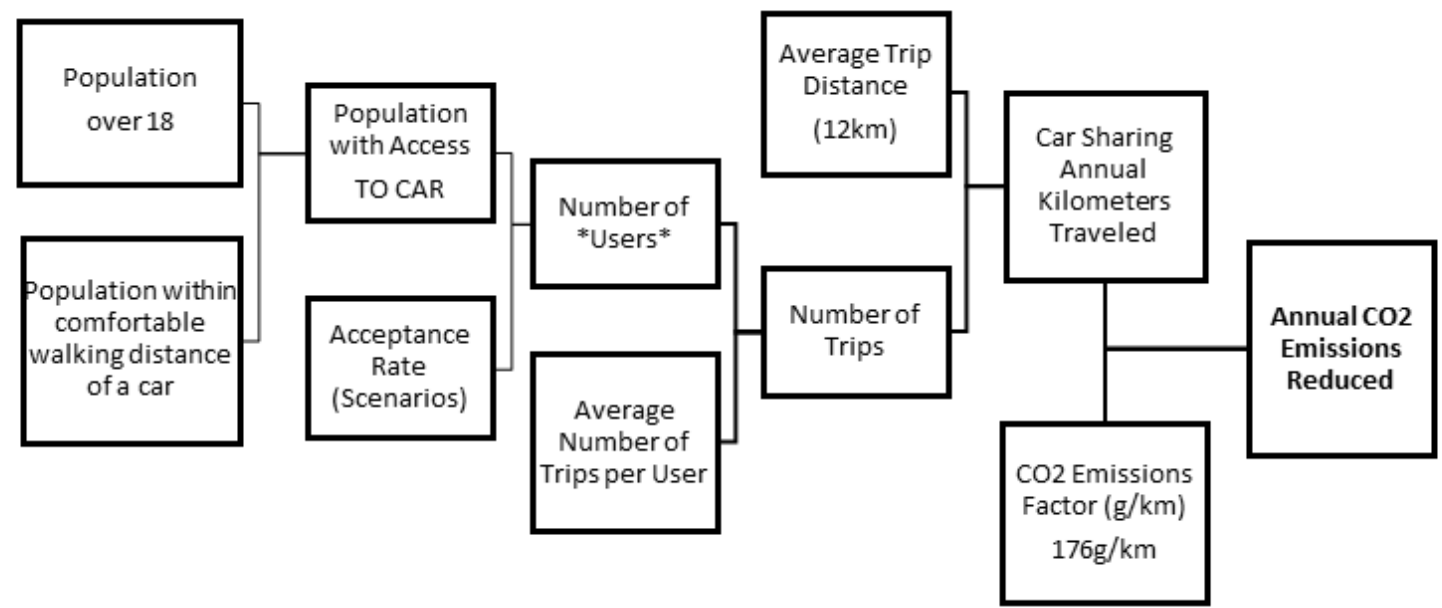

Figure 5: Flow chart of bike sharing $\mathrm{CO} 2$ emissions reduction calculation

CO2 reduction model formula:

Annual CO2 Emission Reduced $=$

Population with access (To Car) * Acceptance rate * Monthly usage frequency *Average trip distance * CO2 emission factor * 12 months

Variable definition:

Population with access (To Car) - Number of residents within the stations' attractive buffer $(250 \mathrm{~m}$ radius for each station) and older than 18

Monthly usage frequency - 2 times per month per accessible user [10]

Average trip distance - $12 \mathrm{~km}$ per trip [10]

CO2 emission factor - $176 \mathrm{~g} / \mathrm{km} \mathrm{CO} 2$ emission of private car [11]

Acceptance rate - defined by the prediction of accessible travelers' acceptance level and willing to use the E-car sharing system. With consideration of new introduction of the system, conservatively choose the best, medium and worst scenarios as $35 \%, 25 \%$, and $15 \%$.

Calculation and Results:

Table 3: Emission reduction calculation results

\begin{tabular}{ccccccc}
\hline $\begin{array}{c}\text { Population } \\
\text { with Access }\end{array}$ & $\begin{array}{c}\text { Accepta } \\
\text { nce Rate }\end{array}$ & $\begin{array}{c}\text { Usage } \\
\text { Frequency } \\
\text { (per month) }\end{array}$ & $\begin{array}{c}\text { Average } \\
\text { Trip } \\
\text { Distance } \\
\text { (km) }\end{array}$ & $\begin{array}{c}\text { CO2 } \\
\text { Emissions } \\
\text { Factor } \\
\text { (g/km) }\end{array}$ & $\begin{array}{c}\text { Emission } \\
\text { per Year (kg) }\end{array}$ & $\begin{array}{c}\text { Total in 15 } \\
\text { Years(ton) }\end{array}$ \\
\hline 14,687 & $35 \%$ & 2 & 12 & 176 & $260,559.12$ & 3908.386 \\
14,687 & $25 \%$ & 2 & 12 & 176 & $186,113.66$ & 2791.704 \\
14,687 & $15 \%$ & 2 & 12 & 176 & $111,668.19$ & 1675.022 \\
\hline
\end{tabular}

\subsubsection{Bike Sharing CO2 Emission Reduction Calculation}




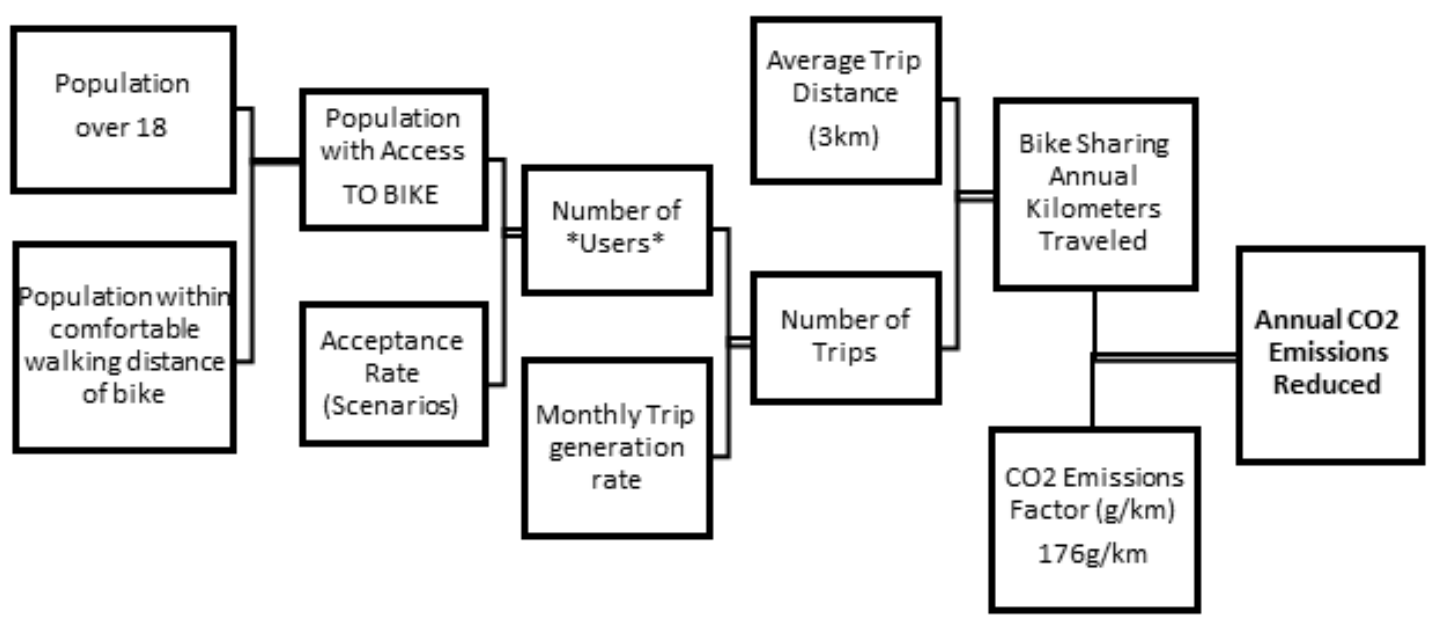

Figure 6: Flow chart of bike sharing $\mathrm{CO} 2$ emission reduction calculation

Reduction model formula:

Annual CO2 Emission Reduced =

Population with access (To Bike) * Acceptance rate* Monthly trips per user * Average trip distance * CO2 emission factor *12 months

Variable definition:

Population with access (To Bike) - Number of residents within the stations' attractive buffer $(250 \mathrm{~m}$ radius for each station) and older than 18 .

Monthly usage frequency - 1 trip per 40 users (conservative rate) $* 30$ days [9]

Average trip distance - $3 \mathrm{~km}$ per trip [9]

CO2 emission factor - $176 \mathrm{~g} / \mathrm{km} \mathrm{CO} 2$ emission of private car [11]

Acceptance rate - defined by the prediction of accessible travelers' acceptance level and willing to use the Bike sharing system. With consideration of new introduction of the system, conservatively choose the best, medium and worst Scenarios as 35\%, 25\%, and $15 \%$.

Calculation and Results

Table 4: Emission reduction calculation results

\begin{tabular}{ccccccc}
\hline $\begin{array}{c}\text { Population } \\
\text { with Access }\end{array}$ & $\begin{array}{c}\text { Acceptance } \\
\text { Rate }\end{array}$ & $\begin{array}{c}\text { Usage } \\
\text { Frequency } \\
\text { (per month) }\end{array}$ & $\begin{array}{c}\text { Average } \\
\text { Trip } \\
\text { Distance } \\
\text { (km) }\end{array}$ & $\begin{array}{c}\text { CO2 } \\
\text { Emissions } \\
\text { Factor } \\
\text { (g/km) }\end{array}$ & $\begin{array}{c}\text { Emission } \\
\text { per Year } \\
\text { (kg) }\end{array}$ & $\begin{array}{c}\text { Total in 15 } \\
\text { Years(ton) }\end{array}$ \\
\hline 23,315 & $35 \%$ & 0.75 & 3 & 176 & $38,777.51$ & 581.6626 \\
23,315 & $25 \%$ & 0.75 & 3 & 176 & $27,698.22$ & 415.4733 \\
23,315 & $15 \%$ & 0.75 & 3 & 176 & $16,618.93$ & 249.2839 \\
\hline
\end{tabular}

\subsubsection{Combination of Bike and Car Sharing}

Total emission reduction (In 15 years) equals to E-Car Sharing CO2 Emission Reduction plus Bike Sharing CO2 Emission Reduction.

Total emission reduction $=E$ - car sharing (reduction) + Bike sharing(reduction)

Best scenarios assumption:

Assume Bike and E-car sharing system with best acceptance scenarios of $35 \%$. The progress result of the total equivalent $\mathrm{CO} 2$ emission reduction in 15 years will be 4490 tons.

Worst scenarios assumption:

Assume Bike and E-car sharing system with worst acceptance scenarios of $15 \%$. The progress result of the total equivalent $\mathrm{CO} 2$ emission reduction in 15 years will be 1924 tons.

Results of Comparison with the original Goal

For this indicator, original project target from the transport sector is to reduce 4110 tons equivalent $\mathrm{CO} 2$ emission in 15 years. Nevertheless, progress results are in the range of 1924 tons (worst scenarios) to 4490 tons (best scenarios). Consequently, the goal would only be archived with best scenarios.

\section{DISCUSSION AND OUTLOOK}

From the results of adapting the 3-tiers mobility stations system in the case study of Fürstenfeldbruck city, efficient travel will indirectly reduce emission emitted from private cars. Nevertheless, the vague existing condition of emission from vehicle make it hard to compare and evaluate. Therefore, providing assumptions and scenarios is the proper way to measure how mobility station will affect travel. Three scenarios are being selected in emission evaluation of 3-tier mobility station implementation. There are 35\% acceptance level for best scenario, $25 \%$ acceptance level for medium scenario, and $15 \%$ acceptance level for worst scenario. Using those scenarios, two different calculations are done, one for car- 
sharing emission reduction calculation and the other is for bike sharing emissions reduction calculation. The result of emission reduction calculation is the goal can only be achieved if best scenario applied or $35 \%$ of accessible user use the 3-Tier mobility station system.

However, due to the construction restraints and the potentially low early acceptance of the system from Fürstenfeldbruck inhabitants, it is appropriate to adjust. Dividing up the development and implementation stages into phases would allow the expenses of the system to be spread out over a longer period, and the residents of the city to be slowly introduced to the mobility station system. Additionally, a concept of equal geographic spread of the stations throughout the project's implementation was used to design the phases. Instead of bundling stations into phases by their geographic location, each phase contains stations from different parts of the city. This was done to more evenly distribute access to the mobility stations during all project phases, as opposed to only building out the stations one specific part of the city in each phase. As a side benefit, this strategy prevents the clustering of mobility station construction sites in one part of the city during any one phase, potentially disrupting street traffic and the quality of life of its residents.

\section{References}

1. David H. Ambroz, Renee Dake Wilson, Robert L. Ahn. Mobility Hubs, (2012). A Reader's Guide. http://www.urbandesignla.com.resourcesdocsMobilit yHubsReadersGuideloMobilityHubsReadersGuide.p df

2. Zukunftnetz Mobilität NRW, Ministeriums für Bauen, Wohnen, Stadtentwicklung und Verkehr des Landes Nordrhein-Westfalen, (2015). Handbuch Mobilstationen Nordrhein-Westfalen. http://www.zukunftsnetz-

mobilitaet.nrw.de/sites/default/files/downloads/20 15-10-

14_handbuch_mobilstationen_nrw_download_ne u.pdf

3. MVV. (2010) MID Studie-Erreichbarkeit des Arbeitsplatzes mit ÖV, Mobilität im Landkreis Fürstenfeldbruck.

https:/www.yumpu.com/de/document/view/1072 9084/mobilitat-im-landkreis-furstenfeldbruck$\mathrm{mvv}$

4. MVV. (2010) Mobilitaet In Landkreis Fuerstenfeldbruck. Basisdaten Des Muenchner Verkehrs- Und Tarifverbundes. https://www.mvvmuenchen.de/fileadmin/Servicedownloads /mvv_lk_fuerstenfeldbruck.pdf

5. Netzwerk Verkehrssicheres Nordrhein-Westfalen. (2015) Handbuch Mobilstationen NordrheinWestfalen. http://www.zukunftsnetzmobilitaet.nrw.de/sites/default/files/

downloads/2015-10-

14_handbuch_mobilstationen_nrw_download_ne u.pdf
6. Alexa Zierl. (2012) Sustainable Energy Action Plan Fürstenfeldbruck. https://mycovenant.eumayors.eu/docs/seap/612_1 338458346.pdf

7. Seign, Rene. (2014) Model-Based Design Of FreeFloating Carsharing Systems. Doctoral. Universität der Bundeswehr München. https://trid.trb.org/view/1336881

8. Serkan Ural, Ejaz Hussain, Jie Shan. (2011) Building population mapping with aerial imagery and GIS data. International Journal of Applied Earth Observation and Geoinformation. Volume 13, Issue 6, December 2011, Pages 841- 852.

9. The Institute for Transportation Development and Policy (ITDP). (2013) The Bike Sharing Planning Guide in Landes-hauptstadt Kiel. https://www.kiel.de/leben/verkehr/verkehrsplanun $\mathrm{g} /$ verkehrsentwicklung/mobilitaetsstationen/mobil itaetsstationen_fuer_kiel.pdf

10. Frank Hansen, BMW Group. (2014) Mobilität neu denken. Conference: TRENDS IN DER AUTOMOBILITÄT. München.

11. ICCT. (2013) Reducing CO2 and fuel consumption from new cars: Assessing the near-term technology potential in the EU. https://theicct.org/publications/reducing-co2-andfuel-consumption-new-cars-eu 